Canadian Oncology

Nursing Journal

Revue canadienne

de soins infirmiers

en oncologie

Volume 27, Issue 1 • Winter 2017

elSSN: $2368-8076$ 


\title{
The meaning of being an oncology nurse: Investing to make a difference
}

\author{
by Lindsey Ann Davis, Frances Fothergill-Bourbonnais, and Christine McPherson
}

\section{ABSTRACT}

The landscape of cancer care is evolving. Oncology nursing continues to develop and respond to the changing needs of patients with cancer and their families. There is limited understanding of what it means to be an oncology nurse, as well as the factors that facilitate or hinder being an oncology nurse. This study used an interpretive phenomenological approach. Six nurses from two in-patient units in a tertiary care teaching facility were interviewed. The overarching theme, Investing to Make a Difference, reflected how oncology nurses invested in building relationships with patients and their family members and invested in themselves by developing their knowledge and skills and, eventually, their identities as oncology nurses. In turn, these investments enhanced their role, and were seen to make a difference in the lives of patients and their family members by supporting them through the cancer journey. Implications of these findings for oncology nursing are highlighted as they relate to nursing practice, education, research, and leadership.

\section{INTRODUCTION}

The landscape of cancer care continues to evolve with a move toward more out-patient care of oncology patients. However, patients continue to receive in-patient cancer care for surgical treatments, as well as for diagnostics, chemotherapy, symptom management, and palliative care.

Understanding oncology nurses' experiences is important in order to recognize and support their role in patient care, as a cohort of specialized oncology nurses is required to meet the needs of patients with cancer and their families. The Canadian Cancer Society's Advisory Committee on Cancer Statistics (20I5) estimates that almost half of all Canadians will develop cancer in their lifetime and one-quarter will die of the disease. The increase in the number of new cancer cases in Canada

\section{ABOUT THE AUTHORS}

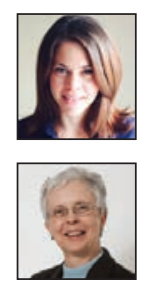

\section{Corresponding author: Lindsey Ann Davis, RN, BScN, MScN \\ lindseyanndf@gmail.com}

Dr. Frances Fothergill-Bourbonnais, RN, BScN, MN, PhD,

Emeritus Professor, University of Ottawa, 451 Smyth Road, RGN 3240, Ottawa, ON K1N 6N5

Telephone: 613-562-5800 ext. 8423; Fax: 613-562-5443

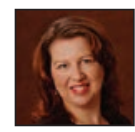

Dr. Christine McPherson, RN, BSc, MSc, PhD, Associate Professor, University of Ottawa, 451 Smyth Road, RGN 3251 D, Ottawa, ON K1N 6N5

Telephone: 613-562-5800 ext. 8394; Fax: 613-562-5443

DOI: $10.5737 / 23688076271914$ over the last 30 years can be attributed to an aging and growing population, as well as enhancements in screening and treatment. The increase is expected to continue as the average number of Canadians 65 years and over is expected to more than double from 4.2 million $(2003-2007)$ to 9.4 million (2028-2032). Specialized oncology nurses will be required to care for these individuals.

This research was guided by the following questions: what is the lived experience of being an oncology nurse in an adult inpatient oncology unit, and what are the factors that facilitate or hinder being an oncology nurse?

\section{LITERATURE REVIEW}

Oncology nursing is demanding both physically and emotionally (Medland, Howard-Ruben \& Whitaker, 2004). Care approaches require addressing the physical, psychosocial and spiritual care needs of patients and their families. Furthermore, oncology care is directed toward "the relief of suffering and support for the best possible quality of life for patients facing serious life-threatening illness..." (Heidrich, 2007, p. 603).

Oncology nurses perceive interdisciplinary conflict, system demands, care restrictions, patients with high acuity and complex needs, emotional demands from intense involvement with patients and families, and dealing with end of life and ethical issues as stressful (de Carvalho, Muller, de Carvalho, \& de Souza Melo, 2005; Grunfeld et al., 2000; Vachon, 200I). However, there is limited research on the experiences of oncology nurses. One example, a hermeneutic investigation by Rittman, Paige, Rivera, Sutphin, and Godown (I997), sought to describe the experience of oncology nurses caring for dying patients. In-depth interviews were conducted with six oncology nurses who had at least five years of oncology nursing experience and had cared for dying patients. Four themes were described: I) "knowing the patient," 2) "preserving hope," 3) "easing the struggle," and 4) "providing for privacy." The researchers concluded that nurses managed the emotional demands of their work by establishing varying degrees of closeness with patients as they were dying. The nurses described developing close bonds with some patients and, despite not developing these relationships with all patients, they felt they provided good care for those who were dying.

\section{METHODS}

According to Steeves, Cohen, and Wise (I994), phenomenological inquiry can provide "a unique view of the nature of oncology nursing” (p.r9) since nurses can reflect on their experiences and the meanings attached to these experiences. Phenomenology is interested in the study of human beings (Heidegger, I962). Heidegger's interpretive phenomenological approach examines human experience in its everydayness 
(Heidegger, I962, p. 69). Heidegger asserts that the only way a researcher can, in fact, carry out interpretive phenomenology is to have prior knowledge of the phenomenon (McConnell-Henry, Chapman, \& Francis, 2009). The first author of this study approached the research process with assumptions and knowledge developed through experiences as an oncology nurse.

Interpretive phenomenology using van Manen's (I990) approach guided this study. The work moves beyond a description of how a phenomenon appears to further uncover and understand the deeper meaning of the experience, as expressed through language and text. van Manen describes hermeneutic phenomenological research as the study of a person's lived experience: the person's reality as it is immediately experienced in the world.

\section{ETHICS}

Ethical approval was obtained from the ethics review board of the health care organization where the study took place and the researchers' academic institution. Presentations related to the study were given to nursing staff in the setting where recruitment occurred to raise awareness of the study and for them to consider participation. Written informed consent was obtained before the interviews.

\section{SAMPLE AND SETTING}

A purposive sampling method was used to recruit oncology nurses from two in-patient oncology units of a I,040-bed, multi-site tertiary care teaching facility in a large urban centre in eastern Ontario. Six nurses (all female) with ages ranging from 23 to more than 50 years agreed to be interviewed. The total years of oncology nursing experience ranged from two to greater than 30 years. Four of the six nurses began their careers on the units selected for this study. The two nursing units were designed to facilitate the provision of care to oncology patients at various stages along their illness trajectories.

The hematology oncology unit was a 23-bed inpatient unit for patients with acute leukemia. The medical oncology unit had 35 beds for patients with a wide array of cancer experiences. Care was centred on diagnostics, chemotherapy, and symptom management, as well as palliative care. To be included in the study, participants needed to be a Registered Nurse currently working on at least one of the aforementioned oncology units, have a minimum of two years of oncology work experience, identify themselves as an oncology nurse, and be English-speaking.

\section{DATA COLLECTION}

Individual unstructured face-to-face interviews were used to guide the exploration of the lived experience of being an oncology nurse. The interviews were conducted by the first author. Open-ended questions such as, "When did you start feeling like an oncology nurse?" and "What does it mean to be an oncology nurse?" were used to elicit nurses' experiences. Interviews lasted 30-60 minutes, were audio taped, and transcribed.

\section{DATA ANALYSIS}

Consistent with Heideggerian phenomenology, van Manen's (I990) approach provided a framework to analyze the transcribed interviews and elicit the essential meaning of the phenomenon. van Manen defined themes within phenomenological research as structures of experience that contributed to understanding the phenomenon. Data from the transcribed interviews were analyzed and guided by the thematic analysis approach outlined by van Manen.

The essential structure of being an oncology nurse unfolded through the use of the holistic, detailed, and selective approaches. The first author read the transcripts as a whole (holistic approach) initially and then line by line (detailed approach). This process fully immersed the researcher in the data. Common words and thoughts from the participants were identified and colour coded during the reading of every interview. Significant statements were then compiled. These statements formed the subthemes. The subthemes identified were then formed into themes. The relationships between the themes were examined within and between each of the interviews. Identification of major themes emerged by observing and interpreting the meaning and context of participants' narrative text and through the process of writing and re-writing. The researchers regularly returned to the transcripts as the writing process unfolded to situate these themes within the phrases and statements shared by the participants (selective approach). All researchers reviewed the transcripts and achieved consensus on the developing themes. If consensus had not been reached the researchers would have returned to the data.

\section{METHODS TO ENSURE TRUSTWORTHINESS}

Lincoln and Guba's (1985) four criteria of trustworthiness were applied, namely, credibility, dependability, confirmability, and transferability. Credibility was met through member checking interviews by returning to the participants with a summary of the themes and categories, and through all researchers agreeing on the developed themes. Credibility was also enhanced as two of the researchers (FFB, CM) were experts in qualitative methods. The criterion of dependability was met through discussion among the researchers throughout the process of analysis, and the development and use of an audit trail to account for, and make transparent, all decisions made by the researchers. To address the criteria of confirmability, a reflexive journal documenting the first author's own beliefs and assumptions was maintained throughout the research process. Transferability of the findings was achieved and made evident through rich descriptions of the themes and descriptions of the participants and the context of their care.

\section{FINDINGS}

The meaning of being an oncology nurse is described in the overarching theme: Investing to Make a Difference. Within the overarching theme, are four themes: Caring for the Whole 
Person, Being an Advocate, Walking a Fine Line, and Feeling Like You are Part of Something Good. The themes and categories are presented in Figure I.

\section{Investing to Make a Difference}

Participants described being invested in the lives of patients, themselves as nurses, and their colleagues. They were committed to journeying alongside patients and families, as they experienced the effects of cancer. At the same time, participants were witness to the suffering of patients and families and tried to connect with them in ways that they perceived as meaningful. Participants also recognized the investment in themselves that was required to ensure they had the necessary clinical knowledge and skills to meet the increasingly specialized needs of oncology patients. Once they felt part of the team, they then could give back to other nurses.

\section{Caring for the Whole Person}

The theme of Caring for the Whole Person reflected the holistic nature of oncology nursing. It comprised three categories: Looking at the Big Picture, Sharing Moments with Patients, and Being in it for the Long Haul. The participants highlighted how they came to know those they cared for in such intimate and familiar ways over the course of often lengthy illnesses. One nurse described, "We are focusing on everything and not just the body systems...You are always dealing with the whole person."

Looking at the Big Picture. Looking at the Big Picture provided nurses with a way to understand their patients' experiences both in and out of hospital. The participants described how they were witness to the many effects of cancer on the psychosocial, physical, and spiritual aspects of patients' lives. As one participant shared, “...there's no subject of your life that your cancer doesn't touch...” Nurses used this knowledge of patients to frame the care they provided, as the following response illustrates: “...it's like looking at all parts of them [patients] and making sure everything is going to work for them [patients] when they go [are discharged from hospital]."

Sharing Moments With Patients. Nurses shared time with patients through moments spent with them. Gestures such as saying a quick hello or spending a few minutes to watch part of a hockey game with a patient gave participants a sense of reward and satisfaction. One participant reflected on comforting a patient in the middle of the night: "...when the person is up wondering what the day is going to bring and you spend that time with them. That is the important stuff."

Being in it for the Long Haul. The journey that participants shared with their patients unfolded over time, as one participant conveyed, “...partly because our patients are in and out through treatment for at least a year...” It was common for oncology patients and their families to endure many and lengthy hospital admissions. All participants' responses reflected a commitment to being with their patients over time throughout all of their hospitalizations. Participants considered this a privilege and a way for patients to develop trust in the relationship they had with participants.

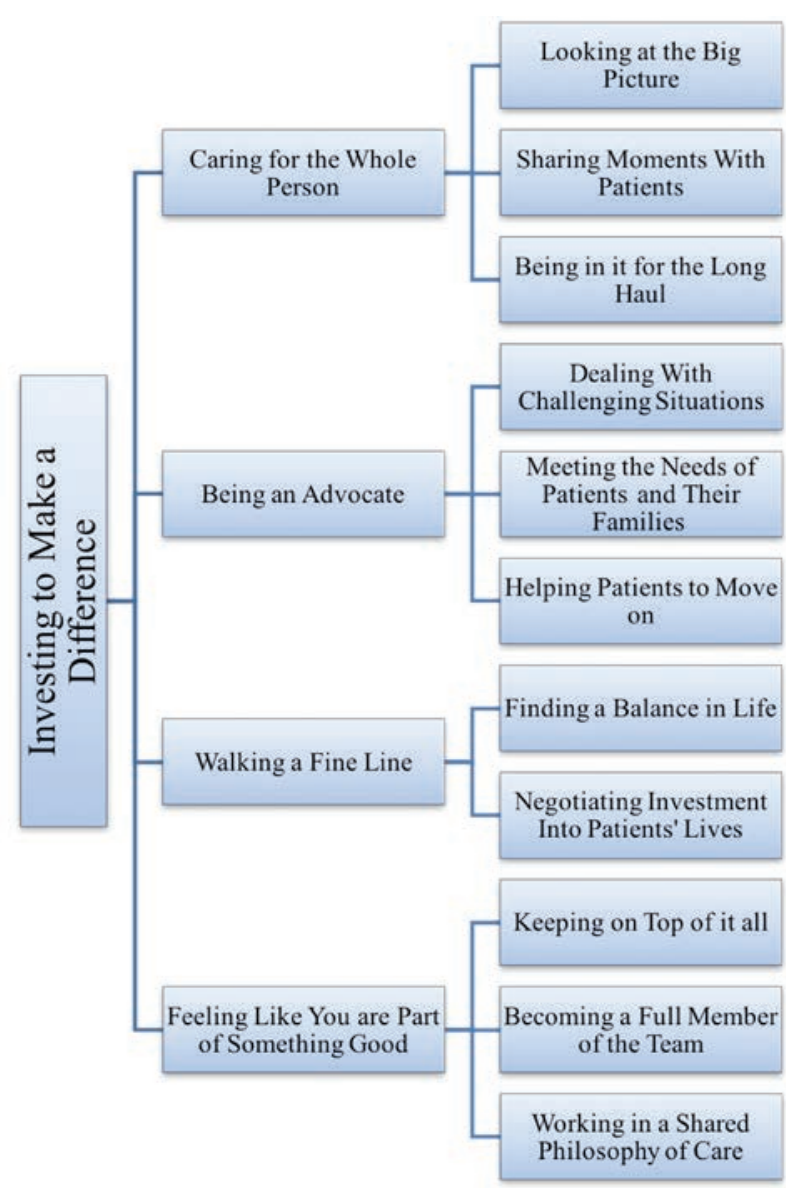

Figure I.

\section{Being an Advocate}

The theme Being an Advocate highlighted the challenges nurses faced in caring for patients and their families and how they persevered to meet the patient and family needs. This theme comprised three categories: Dealing with Challenging Situations, Meeting the Needs of Patients and Their Families, and Helping Patients to Move On. This theme incorporated the ways in which the nurses supported patients in their cancer journey, and the difficulties that the oncology nurses faced in doing so.

Dealing With Challenging Situations. Situations described by participants included, amongst others, caring for patients who were unaware of their prognosis or diagnosis. "You know why they are on the unit...the patient is sitting here all weekend waiting to find out that they have leukemia and to start treatment and no one has actually gone in and talked to them about their bone marrow biopsy..." Incongruity between patients and families or health care professionals regarding the plan of care also presented difficulties, as one nurse reflected: "There are things she still wants in her treatment that aren't going to do her any good and that's hard...you worry about how the end will be for that person." Despite these challenges, participants focused to provide care to patients and their families. "You have got to be strong and have a love for what you do...because even though you are going to help that person, it's not going to be easy."

Meeting the Needs of Patients and Their Families. Participants described meeting patients' needs by helping them to come to 
a realistic understanding of their cancer experience. In order to fully understand the needs of patients and families, participants spent time with them talking and asking questions. A history based on previous interactions during hospitalizations facilitated an understanding of patients' journeys and their needs. "Sometimes people's beliefs are rooted in what they have seen on TV and their grandmother's experience from 50 years ago... one part of the oncology nurse's role is to bring them to the current time and help them understand the current system."

Helping Patients to Move on. Through their interactions with patients, the participants came to know their patients and became aware of their wishes and goals. "It feels great because that's what I am doing it for... and if it means they can function or move on, then that is important." One participant described being overcome with emotion when her patient was discharged from hospital after dealing with many challenges through her hospitalization.

\section{Walking a Fine Line}

The theme Walking a Fine Line reflected the emotional nature of oncology nursing and the balance that was required to deal with these experiences. This theme had two categories: Finding a Balance in Life and Negotiating Investment Into Patients' Lives.

Finding a Balance in Life. The participants described maintaining a balance between their work and home lives and used the analogy of a tightrope walker carrying a balance bar to highlight their experiences. If the bar began to dip too far on either side, the tightrope walker could lose balance. For these oncology nurses, the bar was balanced on one side by their work and on the other by their home lives. On this tightrope, if work situations caused them to teeter to one side, sharing stories with other nurses helped to maintain their course and stay on the straight and narrow. As one participant stated, "to know that they [other oncology nurses] know what you are going through...because people who don't do (what we do) don't always understand it."

Negotiating Investment Into Patients' Lives. Participants' were invested in the patients and families in their care. Over time, participants got to know patients and family members better; they became close and relationships developed over the course of recurrent hospitalizations. However, participants were mindful of the level of their engagement and emotional investment and sought to manage this. As one nurse said, "If you become too subjective then you are not functioning in your role and you are now part of the situation." By managing the level of emotional investment, participants were able to function professionally.

\section{Feeling Like You are Part of Something Good}

The final theme, Feeling Like You are Part of Something Good, reflected participants' experiences as part of a team working toward shared goals. The theme comprised three categories: Keeping on Top of it All, Becoming a Full Member of the Team, and Working in a Shared Philosophy of Care.
Keeping on Top of it All. Participants' identified the types of knowledge and skills required to function in their role as oncology nurses. Ongoing advances in knowledge about the disease and treatment approaches necessitated continual updating to ensure their knowledge was current and relevant. This knowledge included the pathophysiological manifestations of cancer, laboratory values, related complications, and treatments such as chemotherapy regimens. Although keeping up-to-date was identified as a major challenge, this knowledge was imperative to improve nursing practice. One participant reflected, "The biggest challenge is working with the new medications in the field, new chemotherapies and trying to keep on top of it all... and there are always ways of improving your nursing practice."

Becoming a Full Member of the Team. The growth and development of oncology nurses unfolded as they moved from being a novice nurse in oncology, through to embodying confidence and comfort in their role, as valued team members. This process occurred over time. Participants invested in their work and became more confident in their role as oncology nurses. It took at least a year for participants to begin identifying themselves as oncology nurses. With confidence, participants described "giving back" and providing support to other team members. One nurse recalled her encounter with a less-experienced nurse, “I wasn't used to somebody asking me stuff... so it was difficult, and then it was the realization that I had the experience, and I knew what I was doing, so then I felt more like a full member of the team..."

Working in a Shared Philosophy of Care. This category reflected participants' experiences as part of the nursing and inter-professional teams. They described how team members came together to provide care that was situated around one common focus, the patient. While the nurses who were interviewed reflected on their role as oncology nurses, they also recognized that they were part of a team. As one participant remarked, “...you are not alone with the patient...you become part of a bigger group of people [who provides care to the patient...)."

\section{DISCUSSION}

The findings of this study suggested that oncology nurses in this setting viewed their patients through a holistic lens and used this lens to guide their nursing care. The nurses recognized that cancer affected every aspect of patients' lives and their family members. The conceptualization of holism in nursing, as described by Clark (20I2), portrays patients as multidimensional beings where a disruption to one dimension such as the psychosocial, physical, or emotional dimensions can then affect others.

This holistic lens also formed the basis for how nurses in the present study came to know each individual patient and understand their wishes and needs. Relationships were built and fostered through interactions over time and, in some cases, over several years. It is through these relationships that trust, nursing presence, and the therapeutic relationship are cultivated (Carter, 2009). A therapeutic nurse-patient relationship can be described as a helping relationship that is based 
on mutual trust and respect, the nurturing of faith and hope, being sensitive to self and others, and assisting with the gratification of patient's physical, emotional, and spiritual needs through knowledge and skill (Carter, 2009). In providing care to patients and families, oncology nurses may use their physical selves to bring warmth, comfort, and humanness to the experience of suffering that can accompany cancer (Ferrell \& Coyle, 2008).

Knowing the patients in their care meant that these nurses were better able to meet the patient needs and advocate on the patients' behalf. Getting to know patients, as Tanner, Benner, Chesla and Gordon (I993) suggest, includes knowing them not only by expected patterns of response, but as individuals. Patient advocacy, as $\mathrm{Bu}$ and Jezewski (2007) described, is a "process or strategy consisting of a series of specific actions in preserving, representing and/or safeguarding patients' rights, best interests and values in the health care system" (p. I04). Research examining patient advocacy in oncology nursing, has identified three overall advocacy activities: analyzing, counselling and responding (Vaartio-Rajalin \& Leino-Kilpi, 20II). In this study, advocacy was a key nursing role, as nurses had more contact with patients than any other members of the health care team.

The emotionally challenging nature of oncological nursing and the investments made unfolded through the stories the participants shared. The nurses felt as if they made a difference in the lives of their patients over time, as patients journeyed through the trajectory of their illnesses. This emotional investment and the level of engagement with patients and families required balance. This finding was supported by Rittman at al. (I997). Boyle (2000) cited that recognition must be given to psychological and emotional aspects of being an oncology nurse and that its importance must be alongside the sophisticated technical competence required. In the current study, recognition of, and becoming part of the nursing team occurred over time, as competence and confidence developed for this group of oncology nurses. Nursing colleagues provided mentoring and offered support to one another in dealing with patients with complex clinical situations. They also supported one another through the emotional aspects of their work. The "professional network", according to Haavardsholm and Naden (2009), assists in nurses' confidence when this network of colleagues is supportive. The Healthy Work Environment Best Practice Guideline (Registered Nurses Association of Ontario, 2006) lists sharing of expertise as an attribute of teamwork. When nurses feel as if they belong they are more likely to remain employed (Tourangeau, Cummings, Cranley, Ferron, \& Harvey, 20I0). The transition into becoming a full member of the nursing team coincides with the realization that, as nurses, they feel they can meet the needs of their patients and the demands of their roles. In a study of pediatric oncology nurses' first year of nursing, Linder (2009) found that, in addition to gaining confidence and competence, participants perceived that they were legitimate members of the team, as did the participants in the present study.

Time was a thread interwoven throughout all of the themes. Time was required to invest and to make a difference. Time was a key element in establishing and developing relationships with patients and families, since patients often returned to hospital, many times and over several years, for treatments and care. Through time nurses came to know their patients, which helped them to gain insight into their needs and to advocate for them. Providing for the multifaceted needs of patients and their families took time. The participants invested time in working to become clinically competent and, with time, gained knowledge and experience. Time essentially helped nurses to identify themselves as oncology nurses.

\section{IMPLICATIONS FOR ONCOLOGY NURSING}

The findings of this study contribute to the profession's understanding of the meaning of being an oncology nurse and have implications for practice, education, research, and leadership. Time was a key element in establishing and developing relationships with patients and their families. Nurses need to be given the opportunity to develop relationships and to do this they need time to interact with patients and families. Nursing leaders need to recognize the time required to support patients and their families and to recognize the nursing actions that provide support, as part of nursing practice.

In this current study, moments in time were used to make a difference. Perry (2008), described oncology nurses' experiences as having moments of connection and making moments matter. Nurses walked the journey with patients, as they built relationships over time due to the many hospitalizations required. Nurses facilitated this journey by helping patients to move on through the transition to recovery or to end of life. Corner (I997) has emphasized that this nursing work of journeying with patients needs to be recognized

The meaning that nurses assign to their experiences is contextualized by the environments in which they work. It is embedded within their interactions with patients, as nurses respond to patient needs in these environments (Edvardsson, Sandman, \& Rasmussen, 2006). When a nursing environment provides support, it is more likely to retain nurses and have those nurses continue to invest in their work environment. This study highlights the value that nurses place on receiving support from one another, as it relates to attaining emotional well-being and confidence, as well as knowledge, judgement, and skill acquisition. In addition, when nurses feel supported and feel part of the inter-professional team, they are able to further invest in and give back to the team and the nursing unit. Cohen, Ferrell, Vrabel, Visovsky, and Schaefer (20IO) indicate that oncology nurses need support to be able to do their work.

Being an oncology nurse in this study meant an investment in the development of knowledge and skills. This included keeping up-to-date with treatment modalities and nursing practices. Knowledge and skill can be shaped and further refined through personal and professional experiences. (Cohen, I995; Kendall, 2006). Hospitals can pair with an education and mentoring organization to promote oncology nursing knowledge and development through mentoring initiatives. 


\section{CONCLUSION}

The findings of this study contribute to the nursing profession's understanding of the meaning of being an oncology nurse. Oncology nurses invest in their personal and professional lives in order to make a difference in the lives of patients and families who face cancer. Being an oncology nurse requires time: time to spend with patients, time to connect with patients and families, and time to reflect upon their experiences and to share them with others. In addition, they need time to continue to develop clinical knowledge and skills in order to provide purposeful care that meets the needs of their patients.

\section{REFERENCES}

Boyle, D. (2000). Pathos in practice: Exploring the affective domain of oncology nursing. Oncology Nursing Forum, 27, 915-919.

$\mathrm{Bu}, \mathrm{X}$. \& Jezewski, M. (2007). Developing a mid-range theory of patient advocacy through concept analysis. Journal of Advanced Nursing, 57(I), IOI-IIO.

Canadian Cancer Society's Advisory Committee on Cancer Statistics. (2015). Canadian Cancer Statistics 2015: Predictions of the future burden of cancer in Canada. Retrieved from http://www.cancer.ca/ / media/cancer.ca/CW/cancer\%2 oinformation/cancer\%20IOI/ Canadian\%2ocancer\%2ostatistics/Canadian-Cancer-Statistics20I5-EN.pdf?la=en

Carter, M. (2009). Trust, power, and vulnerability: A discourse on helping in nursing. Nursing Clinics of North America, 44(4), 393-405.

Clark, C. (20I2). Beyond holism: Incorporating an integral approach to support caring-healing-sustainable nursing practices. Holistic Nursing Practice, 26(2), 92-102.

Cohen, M.Z. (I995). The meaning of cancer and oncology nursing: Link to effective care. Seminars in Oncology Nursing, 11(I), 59-67.

Cohen, M.Z., Ferrell, B.R., Vrabel, M., Visovsky, C., \& Schaefer, B. (2010). What does it mean to be an oncology nurse? Re-examining the life cycle concepts. Oncology Nursing Forum, 17(5), 56I-570.

Corner, J. (I997). Beyond survival rates and side effects: Cancer nursing as therapy. Cancer Nursing, 2O(I), 3-II.

de Carvalho, E.C., Muller, M., de Carvalho, P.B., \& de Souza Melo, A. (2005). Stress and the professional practice of oncology nurses. Cancer Nursing, 28(3), I87-I92.

Edvardsson, D., Sandman, P., \& Rasmussen, B. (2006). Caring or uncaring: Meanings of being in an oncology environment. Journal of Advance Nursing, 55(2), I88-I97.

Ferrell, B., \& Coyle, N. (2008). The nature of suffering and the goals of nursing. Oncology Nursing Forum, 35(2), 24I-247.

Grunfeld, E., Whelan, T., Zitzelsberger, L., Willan, A., Montesanto, B., $\&$ Evans, W. (2000). Cancer care workers in Ontario: Prevalence of burnout, job stress and job satisfaction. Canadian Medical Association Journal, 163, 166-169.

Haavardsholm, I., \& Naden, D. (2009). The concept of confidencethe nurse's perception. European Journal of Cancer Care, 18, 483-49I.

Heidegger, M. (I962). Being and time (J. MacQuarrie \& E. Robinson, Trans.). New York: Harper \& Row Publishers. (original work published in I927 Sein und Zeit, Gesamtausgabe, 2).
Oncology nurses commit to their own knowledge and skill development and to supporting the development of their fellow nurses. They also become contributing members of the team. In giving back to their team they continue to give and receive support within the structure of the nursing unit. The structure of a supportive team environment can sustain oncology nurses' ability to continue to make a difference in the lives of others.

\section{ACKNOWLEDGEMENTS}

We thank Dr. Cynthia Toman and Inara Karrei for their support in this research.

Heidrich, D. (2007). Palliative care. In M.E. Langhorne, J.S. Fulton, \&

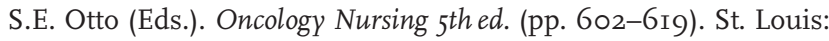
Elsevier.

Kendall, S. (2006). Admiring courage: Nurses' perceptions of caring for patients with cancer. European Journal of Oncology Nursing, 10(5), 324-334.

Lincoln, Y., \& Guba, E. (1985). Naturalistic inquiry. Beverly Hills: Sage Publications.

Linder, L. (2009). Experiences of pediatric oncology nurses: The first year of hire. Journal of Pediatric Oncology Nursing, 26(I), 29-40.

McConnell-Henry, T., Chapman, Y., \& Francis, K. (2009). Husserl and Heidegger: Exploring the disparity. International Journal of Nursing Practice, 15, 7-I5.

Medland, J., Howard-Ruben, J. \& Whitaker, E. (2004). Fostering psychosocial wellness in oncology nurses: Addressing burnout and social support in the workplace. Oncology Nursing Forum, 31(I), 47-54.

Perry, B. (2008). Why exemplary oncology nurses seem to avoid compassion fatigue. Canadian Oncology Nursing Journal, 18(2), 87-99.

Registered Nurses' Association of Ontario. (2006). Collaborative practice among nursing teams. Retrieved from http://rnao.ca/sites/ rnaoca/files/Collaborative_Practice_Among_Nursing_Teams.pdf

Rittman, M., Paige, P., Rivera, J., Sutphin, L., \& Godown, I. (I997). phenomenological study of nurses caring for dying patients. Cancer Nursing, 2O(2), II5-II9.

Steeves, R., Cohen, M.Z., \& Wise, C. (I994). An analysis of critical incidents describing the essence of oncology nursing. Oncology Nursing Forum, 21(8 Suppl.), 9-I7.

Tanner, C.A., Benner, P., Chesla, C., \& Gordon, D.R. (I993). The Phenomenology of knowing the patient. Journal of Nursing Scholarship, 25(4), 273-280.

Tourangeau, A., Cummings, G., Cranley, L., Ferron, E., \& Harvey S. (20IO) Determinants of hospital nurse intention to remain employed: Broadening our understanding. Journal of Advanced Nursing, 66(I), 22-32.

Vaartio-Rajalin, H., \& Leino-Kilpi, H. (20II) Nurses as patient advocates in oncology care: Activities based on literature. Clinical Journal of Oncology Nursing, 15(5), 526-32.

Vachon, M.L.S. (200I). The nurses' role: The world of palliative care nursing. In B.R. Ferrell \& N. Coyle (Eds.). Textbook of palliative nursing (pp. 647-662). New York: Oxford University Press.

van Manen, M. (I990). Researching lived experience: Human science for an action sensitive pedagogy. London, Ontario, Canada: Althouse Press. 